\title{
Total Phenolic Content and Antioxidant Activity of Seed Extract of Lagerstroemia Speciosa L.
}

\author{
SYED JUNAID, K N. RAKESH, N. DILEEP, G. POORNIMA*, \\ T. R. PRASHITH KEKUDA and S. MUKUNDA
}

Department of Microbiology, SRNMN College of Applied Sciences, NES Campus, Balraj Urs Road, Shivamogga-577201, Karnataka, India poo.an30@gmail.com

Received 15 July 2012 / Accepted 16 August 2012

\begin{abstract}
Total phenol content and antioxidant activity of methanol extract of dried seeds of Lagerstroemia speciosa were determined. The authenticated samples of seeds were powdered and extracted using methanol. The total phenolic content of extract was estimated by Folin-Ciocalteau method. Radical scavenging and reducing activity of seed extract was determined by DPPH free radical scavenging assay and Ferric reducing assay. The extract was found to possess an appreciable quantity of phenolic substances $(325 \pm 0.01 \mu \mathrm{g}$ gallic acid equivalents $/ \mathrm{mg}$ extract). A dose dependent scavenging activity in DPPH assay with $\mathrm{IC}_{50}$ value of $9.63 \pm 0.20 \mu \mathrm{g} / \mathrm{mL}$ was observed. The extract showed concentration dependent reducing activity as revealed by an increase in the absorbance of reaction mixture. The observed activity of seed extract could be related to the presence of phenolic substances.
\end{abstract}

Keywords: Lagerstroemia speciosa, Antioxidant, DPPH, Ferric reducing, Folin-Ciocalteau

\section{Introduction}

Lagerstroemia speciosa synonym Lagerstroemia flos-reginde Retz. Belongs to the family Lythraceae and is distributed in Tropical Himalaya and Assam, Western and Eastern Ghats, up to 1000 m. It is known as Pride of India, Queen's Flowers and Queen Crape Myrtle in English. Seed is narcotic. Root is astringent, stimulant, febrifuge. Fruit is used for aphthae of the mouth. Leaves are used as purgative, diuretic and deobstruent. An infusion of bark is given in diarrhoea and abdominal pain. A decoction of the leaves, also of dried fruits, is used like tea for diabetes mellitus in Philippines. The plant contains triterpenoids, colocolic acid and maslinic acid. Colocolic acid is known to possess hypoglycemic activity. Leaves contain lageracetal and sitosterol. Ellagitannins have been isolated from fruits and leaves ${ }^{1}$. Nonanedioic acid, 12-acetyloxy-9-octadecenoic acid and 16-methyl-heptadecanoic acid were isolated from petroleum ether extract of seeds. The fraction containing these compounds has shown to possess antibacterial activity ${ }^{2}$. The hot water extract and the methanol 
eluent of leaves were shown to stimulate glucose uptake in 3T3-L1 adipocytes with an induction time and a dose-dependent response similar to those of insulin ${ }^{3}$. Hayashi et al. ${ }^{4}$ isolated ellagitannins, lagerstroemin, flosin $\mathrm{B}$ and reginin $\mathrm{A}$ by bioassay-guided fractionation of the aqueous acetone extract of the leaves and observed increased glucose uptake of rat adipocytes by the compounds. Hypoglycemic effects of spray dried powder and decoction on alloxan-induced diabetic mice was investigated and both significantly reduced blood and urinary glucose levels from $8^{\text {th }}$ day to $28^{\text {th }}$ day . Aqueous extract of leaf was shown to cause marked inhibition of bacteria than ethanol extract ${ }^{6}$. Saha et al. ${ }^{7}$ evaluated hypoglycemic effect of leaves hot water extract on streptozotocin induced diabetes in rats. Treatment with hot water extract depressed the high blood sugar level and increased the activity of shunt enzyme glucose-6-phosphate dehydrogenase and glutathione level. The depression of the activity of hepatic gluconeogenic enzymes glucose-6-phasphatase and fructose-1,6-bisphosphatase was observed. In antinociceptive activity study by acetic acidinduced gastric pain model in Swiss albino mice, the bark chloroform extract exhibited significant inhibition of writhing at the highest dose tested ${ }^{8}$. The root extract showed significant hepatoprotective activity of root extract in $\mathrm{CCL}_{4}$ induced hepatotoxicity. A decrease of serum liver marker enzymes along with increase in GSH, SOD and catalase activity was observed ${ }^{9}$. The leaf extract was shown to possess marked antioxidant activity ${ }^{10}$. In a study by Rahman et al. ${ }^{11}$, the ethanol extract of dried fruits produced significant writhing inhibition in acetic acid-induced writhing in mice and found to possess antidiarrhoeal activity on castor oil induced diarrhoea in mice. The extract also produced the most prominent cytotoxic activity against brine shrimp Artemiasalinawith an $\mathrm{LC}_{50}$ of 60 $\mathrm{g} / \mathrm{mL}$. Literature review revealed that antioxidant activity of seed extract of $L$. speciosa remains unexplored. Hence, in this study, we determined antioxidant activity and total phenol content of dried seed extract of $L$. speciosa.

\section{Experimental}

The seeds from mature fruits were collected during April 2012 from the college campus, authenticated and voucher specimen (SRNMN/MB/SRD-05) was deposited in the department herbaria for future reference. The seeds were dried and powdered mechanically. A known quantity of powdered material $(100 \mathrm{~g})$ was subjected to soxhlation and exhaustively extracted with methanol (HiMedia, Mumbai) for about 48 hours. The extract was filtered and concentrated in vacuum under reduced pressure and dried in the desiccator ${ }^{12}$.

\section{Total phenolic content of seed extract}

Total phenol content of dried seed extract was determined by Folin-Ciocalteu method. A dilute concentration of extract $(0.5 \mathrm{~mL})$ was mixed with $0.5 \mathrm{~mL}$ of $1: 1$ diluted FolinCiocalteu reagent and $4 \mathrm{~mL}$ of sodium carbonate $(1 \mathrm{M})$. The mixtures were allowed to stand for 15 minutes and the total phenol content was determined colorimetrically at $765 \mathrm{~nm}$. A standard curve was prepared by using an increasing concentration of gallic acid in methanol. A standard curve was plotted using different concentrations of gallic acid (standard, $0-1000 \mu \mathrm{g} / \mathrm{mL})$. Total phenolic content was estimated as $\mu \mathrm{g}$ gallic acid equivalents $(\mathrm{GAE}) / \mathrm{mg}$ of extract ${ }^{12}$.

\section{Antioxidant activity of seed extract}

DPPH free radical scavenging assay

The radical scavenging ability of seed extract and Ascorbic acid (standard) was tested on the basis of the radical scavenging effect on the DPPH free radical. In clean and labeled test 
tubes, $2 \mathrm{~mL}$ of DPPH solution $(0.002 \%$ in methanol) was mixed with $2 \mathrm{~mL}$ of different concentrations (10 to $400 \mu \mathrm{g} / \mathrm{mL}$ of methanol) of extract and standard separately. The tubes were incubated at room temperature in dark for 30 minutes and the optical density was measured at $517 \mathrm{~nm}$ using UV-Vis spectrophotometer. The absorbance of the DPPH control was also noted. The scavenging activity of the extract was calculated using the formula: Scavenging activity $(\%)=[(\mathrm{A}-\mathrm{B}) / \mathrm{A}] \times 100$, where A is absorbance of DPPH and B is absorbance of DPPH and extract/standard combination ${ }^{12}$. The $\mathrm{IC}_{50}$ value for the extract was calculated by Origin 6.0 software. $\mathrm{IC}_{50}$ denotes the concentration of extract required to scavenge $50 \%$ of DPPH free radicals.

\section{Ferric reducing assay}

Different concentrations of seed extract and Tannic acid (standard), namely 10 to $400 \mu \mathrm{g} / \mathrm{mL}$, in $1 \mathrm{~mL}$ of methanol were mixed in separate tubes with $2.5 \mathrm{~mL}$ of phosphate buffer (200 mM, pH 6.6) and $2.5 \mathrm{~mL}$ of $1 \%$ potassium ferricyanide. The tubes were placed in water bath for 20 minutes at $50{ }^{\circ} \mathrm{C}$, cooled rapidly and mixed with $2.5 \mathrm{~mL}$ of $10 \%$ trichloroacetic acid and $0.5 \mathrm{~mL}$ of $0.1 \%$ Ferric chloride. The amount of iron(II)-ferricyanide complex formed was determined by measuring the formation of Perl's Prussian blue at $700 \mathrm{~nm}$ after 10 minutes. The increase in absorbance of the reaction mixtures indicates increased reducing power ${ }^{12}$.

\section{Statistical analysis}

All data were expressed as mean \pm Standard deviation of the number ofexperiments (n5). Past softwareversion 1.92 was used.

\section{Results and Discussion}

The amount of total phenols in the seed extract was estimated by the Folin-Ciocalteu method. The content of total phenols is expressed as GAE. The phenolic content of seed extract was found to be $325 \pm 0.01 \mu \mathrm{g} \mathrm{GAE} / \mathrm{mg}$ extract.

Antioxidant activity of different concentrations of seed extract and ascorbic acid in terms of free radical scavenging ability was evaluated using DPPH free radical assay (Figure 1). The extract exhibited marked antioxidant activity by scavenging $\mathrm{DPPH}^{*}$ (free radical) and converting into DPPHH and the activity was found to be dose dependent. The scavenging activity of ascorbic acid was greater than that of methanol extract. The $\mathrm{IC}_{50}$ value for the extract was found to be $9.63 \pm 0.20 \mu \mathrm{g} / \mathrm{mL}$.

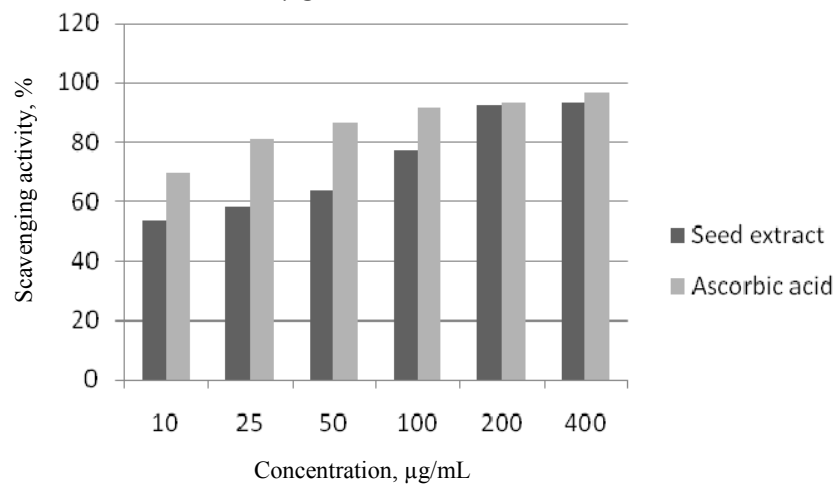

Figure 1. DPPH radical scavenging activity of extract and ascorbic acid 
In order to examine the reducing power of extract, the reduction of $\mathrm{Fe}^{3+}$ to $\mathrm{Fe}^{2+}$ was investigated in the presence of extract and standard (tannic acid). The result of reducing power of different concentrations of extract and tannic acid is presented in Figure 2. The absorbance at $700 \mathrm{~nm}$ was found to increase with the concentration and is indicating reducing power of extract and standard.

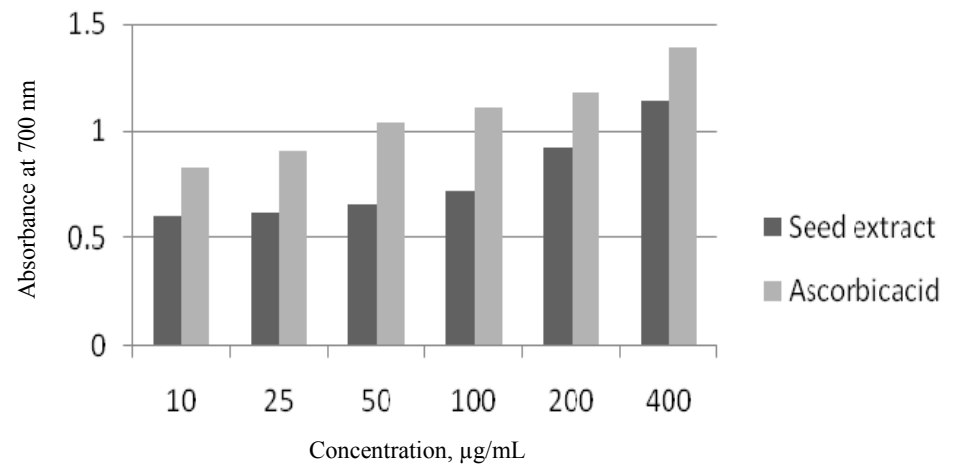

Figure 2. Ferric reducing activity of extract and tannic acid

Oxidative stress is implicated in over one hundred human diseases, such as cancer, cardiovascular disease, aging and neurodegenerative diseases. The innate defense in the human body, however, may not be enough in case of severe oxidative stress. Therefore, certain amounts of exogenous antioxidants are constantly needed to maintain an adequate level of antioxidants in the body ${ }^{13}$. Free radicals play an important role in some pathogenesis of serious diseases. Compounds that can scavenge free radicals have great potential in ameliorating these diseases. Antioxidants are substances that can prevent or delay oxidative damage of lipids, proteins and nucleic acids by reactive oxygen species, which include reactive free radicals such as superoxide, hydroxyl, peroxyl, alkoxyl and non- radicals such as hydrogen peroxide, hypochlorous, etc. They scavenge radicals by inhibiting initiation and breaking chain propagation or suppressing formation of free radicals by binding to the metal ions, reducing hydrogen peroxide and quenching superoxide and singlet oxygen ${ }^{14}$.

Recent developments in medicine pointed out that free radicals are involved in many diseases. Synthetic antioxidants such as butylhydroxyanisole, butylhydroxytoluene or propyl gallate have been widely used as antioxidants but are reported to be carcinogenic and mutagenic on chronic consumption ${ }^{15-16}$. Hence, discovery of new, safe and effective antioxidants particularly from natural sources is of considerable interest in preventive medicine. Crude extracts of herbs, spices and other plant materials rich in phenolics are of increasing interest in the food industry because they retard oxidative degradation of lipids and thereby improve the quality and nutritional value of food. Polyphenolic compounds are commonly found in both edible and inedible plants and they have been reported to have multiple biological effects, including antioxidant activity. Due to the presence of the conjugated ring structures and hydroxyl groups, many phenolic compounds have the potential to function as antioxidants ${ }^{17-18}$.

DPPH is relatively stable nitrogen centered free radical that easily accepts an electron or hydrogen radical to become a stable diamagnetic molecule ${ }^{19}$. DPPH radicals react with suitable reducing agents as a result of which the electrons become paired off forming the corresponding hydrazine. The solution therefore loses color stoichometrically depending on 
the number of electrons taken up $^{20}$. The free radical scavenging activity of the seed extract was measured by measuring the decrease in absorbance of methanolic DPPH solution at $517 \mathrm{~nm}$ in the presence of the extract. The bleaching of the DPPH solution increased with increasing amount of extract in a given volume of solution. The concentration of extract required to scavenge $50 \%$ of $\mathrm{DPPH}, \mathrm{IC}_{50}$, was found to be $9.63 \mu \mathrm{g} / \mathrm{mL}$. The bleaching action of seed extract is mainly attributed to the presence of phenolic substances. The lower the $\mathrm{IC}_{50}$ the better it is able to scavenge the radicals ${ }^{14}$.

The reducing activity of seed extract was determined by ferric reducing assay. The reducing capacity of a compound may serve as a significant indicator of its potential antioxidant activity ${ }^{21}$. The presence of reductants such as antioxidant substances in the antioxidant samples causes the reduction of the $\mathrm{Fe}^{3+}$ /ferricyanide complex to the ferrous form. Therefore, $\mathrm{Fe}^{2+}$ can be monitored by measuring the formation of Perl's Prussian blue at $700 \mathrm{~nm}^{22}$. The reductive capabilities in terms of ferric to ferrous transformation were measured in the presence of seed extract and tannic acid. A significant change in reducing power was observed after the concentration of extract increased from $50 \mu \mathrm{g} / \mathrm{mL}$. Reducing power of extract was lesser when compared to tannic acid.

\section{Conclusion}

A marked antioxidant activity of dried seed extract was observed in this study. The observed activity could be related to the presence of appreciable amount of phenolic contents in the extract. In suitable form, the seeds may find use in prevention of oxidative damage caused by free radicals. To the best of our knowledge, this is the first report on antioxidant activity of seed extract. Further studies on toxicity determination and isolation and determination of antioxidant activity of active principles in seeds are to be carried out.

\section{Acknowledgement}

The authors express thanks to Principal, SRNMN College of Applied Sciences, Shivamogga for providing all the facilities to conduct work. Authors also express thanks to NES, Shivamogga for giving moral support.

\section{References}

1. Khare C P, Indian Medicinal Plants- An Illustrated Dictionary; Springer-Verlag: Berlin Heidelberg, 2007, 358-359.

2. Sinhababu A, Das S, Laskar S, Thakur S and Sen S K, Adv Food Sci., 1999, 21(1-2), 19-22.

3. Liu F, Kim J, Li Y, Liu X, Li J and Chen X, J Nutri., 2001, 131, 2242-2247.

4. Hayashi T, Maruyama H, Kasai R, Hattori K, Takasuga S, Hazeki O, Yamasaki K and Tanaka T, Planta Medica., 2002, 68(2), 173-175.

5. Tanquilut N C, Tanquilut M R C, Estacio M A C, Torres E B, Rosario J C and Reyes B A S, J Med Plants Res., 2009, 3(12), 1066-1071.

6. Ambujakshi H R, Surendra V, Haribabu T and Goli D, J Pharmacy Res., 2009, 2(6), 1028.

7. Saha B K, Bhuiyan M N H, Mazumder K and Haque K M F, Bangladesh $J$ Pharmacol., 2009, 4, 79-83.

8. Morshed A, Hossain M H, Shakil S, Nahar K, Rahman S, Ferdausi D, Hossain T, Ahmed I, Chowdhury M H and Rahmatullah M, Adv Natural Appl Sci., 2010, 4(2), 193-197. 
9. Lad P N, Patel N C, Shah V N and Mesariya P S, Int J Pharm Res Development, 2011, 3(6), 110-117.

10. Saumya S M and Basha M P, Int J Pharmacy Pharm Sci., 2011, 3(1), 165-169.

11. Rahman Md A, Uddin N, Hasanuzzaman Md and Rahman A A, Pharmacologyonline, 2011, 1, 604-612.

12. Rekha C, Poornima G, Manasa M, Abhipsa V, Devi J P, Kumar H T V and Kekuda T R P, Chem Sci Trans., 2012, 1(2), 303-310.

13. Li H, Wang X, Li Y, Li P and Wang H, Food Chem., 2009, 112, 454-460.

14. Lim Y Y, Lim T T and Tee J J, Food Chem., 2007, 103, 1003-1008.

15. Ito N, Hirose M, Fukushima S, Tsuda H, Shira T and Tatematsu M, Food Chem Toxicol., 1986, 24, 1071-1082.

16. Behera B C, Verma N, Sonone A and Makhija U, Food Sci. Technol., 2006, 39, 80-85

17. Wojdylo A, Oszmian'ski J and Czemerys R, Food Chem., 2007, 105, 940-949.

18. Liu X, Zhao M, Wang J, Yang B and Jiang Y, J Food Composition Anal., 2008, 21(3), 219-228.

19. Di Mambro V M, Azzolini A E C S, Valim Y M L and Fonseca J V, Int J Pharm., 2003, 262, 93-99.

20. Blois M S, Nature, 1958, 29, 1199.

21. Meir S, Kanner J, Akiri B and Hadas S P, J Agr Food Chem., 1995, 43, 1813-1817.

22. Chung Y C, Chang C T, Chao W W, Lin C F and Chou S T, J Agr Food Chem., 2002, 50, 2454-2458. 